\title{
Perception of Refractive Error among Adolescents - A Pilot Study
}

\author{
Article by Janitha Plackal Ayyappan ${ }^{1}$, Galal Ismail ${ }^{2}$, Kalyani Mohanraj ${ }^{3}$ \\ ${ }^{1}$ University of Buraimi Oman \\ E-mail: janitha.a@uob.edu.om ${ }^{1}$
}

\begin{abstract}
Background: Several studies reported about the prevalence of refractive error among children as well as various age group. Hardly any study reported about the perception of refractive error among adolescents. The purpose of the study was to examine the level perception regard to refractive error in adolescents, rural region of India.

Objectives: The aim of the study to find the level of perception of refractive error among adolescents, Andhra Pradesh, India.

Materials and Methods: A purposive sampling method was applied to choose 50 subjects aged between 16 years to 18 years from the rural population of Andhra Pradesh were considered for analysis. A selfdesigned questionnaire with open-ended and closed-ended questions was designed to gather the participants' demographic data such as gender, age, majors, socioeconomic status of the parent, as well as their perception toward refractive error was analysed using a Statistical Package for Social Science (SPSS 10.0.5) (SPSS Inc. Chicago, USA).

Results: A total of 50 participants' $(n=50)$ responded to a five-point Likert's scale comprising of 11test items. Out of the 11 test item, 5 item mean score found between 4.06-4.42 with SD $\pm 0.9-1.3$ showed consistently high responses as "strongly agree". Whereas, four-item mean score ranges from 3.18- 3.86 with $S D \pm 1.3-1.53$ reflected as "agree". Furthermore, 2 test items mean score 4.18-4.36 with SD \pm 1.5-1.6 found the responses as "Neutral". However, there is no test item mean score as "disagree" and "strongly disagree" reported by the participant.

Conclusion: perception of refractive error among adolescents found to be poor in this study.
\end{abstract}

Keyword: Perception, Refractive Error, Adolescents, Refractive Correction and Methods.

\section{Introduction}

Refractive error is considered as one of the central concern of visual impairment. This has a considerable impact on various levels of the age group, socioeconomic status and society (Chia et al. 2004). According to (WHO- 2013) worldwide, 285 million people are suffering due to visual impairment and 85 million people are considered to be blind. The figures of 2010 suggestive of eighty percent impairment related to visual can be preventable. Interestingly; on an average of ninety percent of people with visual impairment are living in developing countries. The recent reports suggest $43 \%$ of visual disability is due to the refractive error (Pascolini \& Mariotti 2012). The consequence of the imperfect optical system in the eye ends up with so-called refractive error, in which condition parallel light rays from infinity while passing through the optical component of the eye focus either short of the retina or beyond instead of the retina (Williams et al. 2015). The uncorrected refractive error can lead to visual impairment, and this has a negative impact on all age groups; children, adolescents, adults and the elderly. The consequences of visual impairment can lead to lack of employment opportunity, financial burden and poor quality of life (Gomez-Salazar et al. 2017). However; the extent of refractive error is not precisely known in all the ages, especially prevalence and perception of refractive error in adolescents of the rural region. Likewise; caring for eyes of adolescents found to be the more challenging task when it comes to their academic front and future perspectives. This scenario will be worse due to the current overexposure to electronic devices such as smartphones, TV, computer and video games (LLK Lin; et al. 1983-2000). The most exciting phenomena found among these 
DOI: $10.21522 / \mathrm{TIJPH} .2013 .06 .02 . A r t 013$

ISSN: $2520-3134$

adolescents; never complaints about visual fatigue or more or less they perceived to be asymptomatic in this age group. Moreover, when it comes to the rural region, the lack of eye care facility also another primary concern. Hence it is essential to investigate the perception of refractive error and their method of corrective option among adolescents.

\section{Method}

The study was conducted in Government Junior College, Palasa. It is a Higher Secondary School, located in the Palasa, a municipal in the district of Srikakulam, Andhra Pradesh, India. It is a school for both boys and girls having 700 scholars enrolled currently.

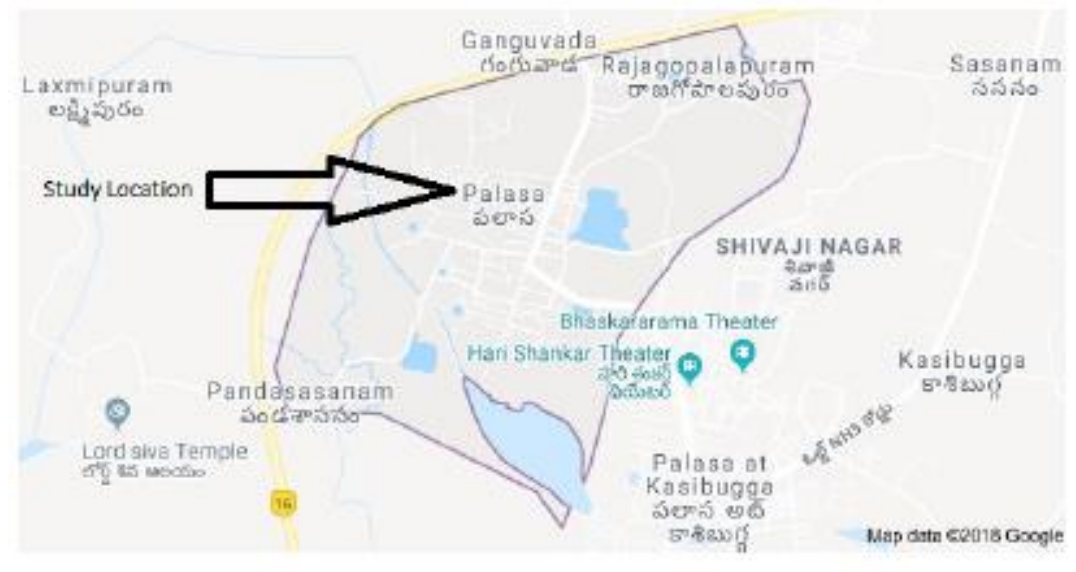

Figure 1. Location of the study

It is a quantitative, cross-sectional, prospective, questionnaire-based pilot study conducted to ensure the level of perception of refractive error among adolescents. A self-designed and validated questionnaire was used to collect the data. The survey was designed from a literature review. However, there were only few literature reviews available about the perception of the refractive error when it comes to the adolescent age group. The survey questions consist of two major components; The first part of the questionnaire consists of demographic details of the participants which includes biophysical data, socioeconomic status, educational status of parents and history of using spectacles for visual error correction among parents and siblings and any other close relatives; While the second part of the questionnaire comprised of questions related to the perception of refractive error. And both open-ended and closed-end items were included for the study. The inclusion criteria for the study was considered as the students who studied in higher secondary school with age ranging between 16 to 18 years; both genders, students who enrolled in different majors like, Maths, biology, Physics (MPC), biology, physics and chemistry (BPC), history, economics and civics (HEC) and commerce, economics and civics (CVC). Also, socioeconomic background of parents, with and without refractive error were included. Total 50 sample was taken for the pilot test. Participants' age above 18years were excluded from the study and participants who are not willing to participate in the survey also exempted from the pilot test. Before conducting a pilot test, the content validation of the questionnaire was tested. Content validation was done by subject experts. To test the internal consistency in the questionnaire tested using a, Cronbach's alpha test has applied the questionnaire. And it showed as 0.815, which is found to be highly consistent the test item Javali, S. B., Gudaganavar, N. V., \& Raj, S. M. (2011). The required permission was obtained from the school authorities before the start of the Pilot test. Likewise, the purpose of the study was explained to the subjects along with informed consent were obtained. The research protocol adhered to the provision of the Declaration of Helsinki for research involving human beings. However, participating in the study were purely involuntary nature. Also, confidentiality was assured to the participants by explaining that, details which were collected will be kept as confidential and it will be used only for research and educational purpose. Furthermore, also ensured that participants could withdraw from the study any point of time between the duration. 


\section{Sampling}

A total of $\mathrm{N}=50$ sample were considered for pilot test. Purposive sampling was done. All students fulfilling the inclusion criteria were added to the study till the required number achieved.

\section{Data management and analysis}

After collecting the completed questionnaire from the respondents, data entered in Microsoft XL spreadsheet after ensuring completeness of the filled forms. The analysis was done using the Statistical

Package for Social Science (SPSS 10.0.5) (SPSS Inc. Chicago, USA). The descriptive statistics used to identify the questionnaire based response related to perception. 


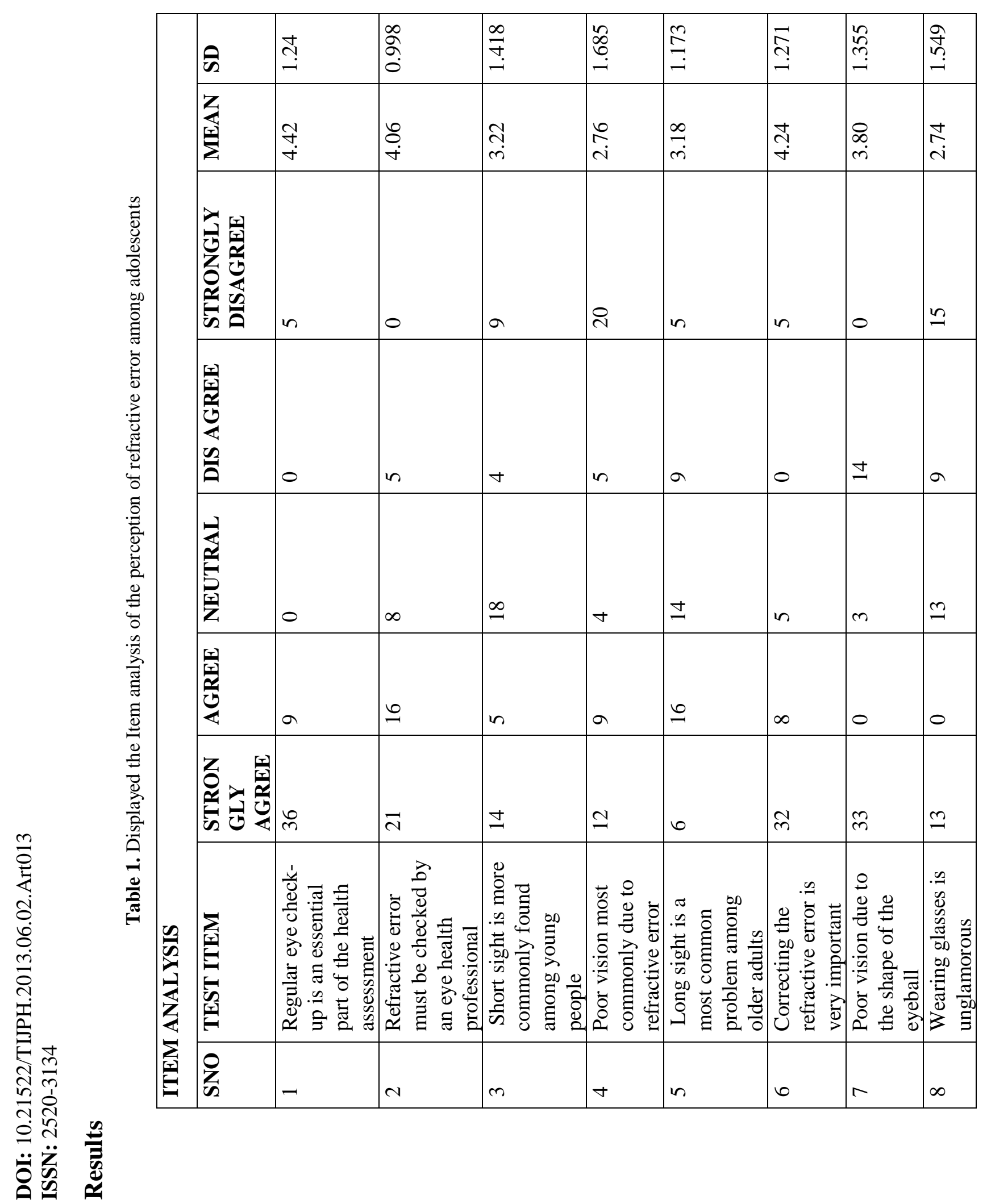




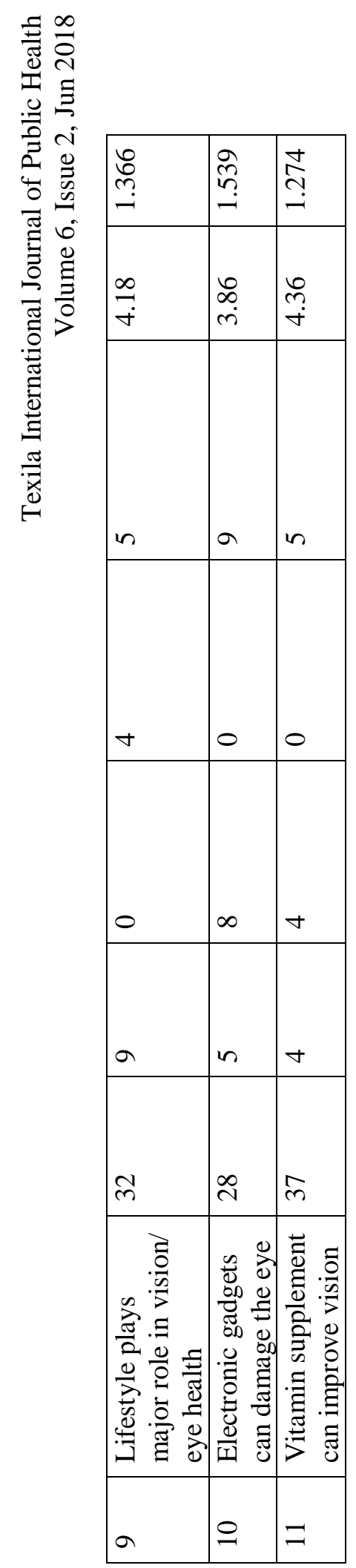


DOI: $10.21522 / \mathrm{TIJPH} .2013 .06 .02 . A r t 013$

ISSN: $2520-3134$

A total of 50 participants' $(\mathrm{n}=50)$ responded to a five-point Likert's scale comprising of 11 test items. For analysis, numerical values were considered as 5, 4, 3,2 \&1 with a statistical limit ranges from the mean score of 4.01-5 (Strongly agree), 3.01-4 (Agree),2.01-3(Neutral), 2.00(Disagree) and 0.01 until 1.0 (Strongly disagree). Out of the 11 test item, 5 item mean score found between $4.06-4.42$ with SD \pm 0.9 1.3 showed consistently high responses as "strongly agree". This includes regular eye check up with professionals and the following correction in the same regard as perceived as very important. Also, vitamin supplements and lifestyle were strongly perceived to influence vision. Whereas, four-item mean score ranges from 3.18- 3.86 with SD $\pm 1.3-1.53$ reflected as "agree". Furthermore, 2 test items mean score 4.184.36 with $\mathrm{SD} \pm 1.5-1.6$ found the responses as "Neutral". However, there is no test item mean score as "disagree" and "strongly disagree" reported by the participant.

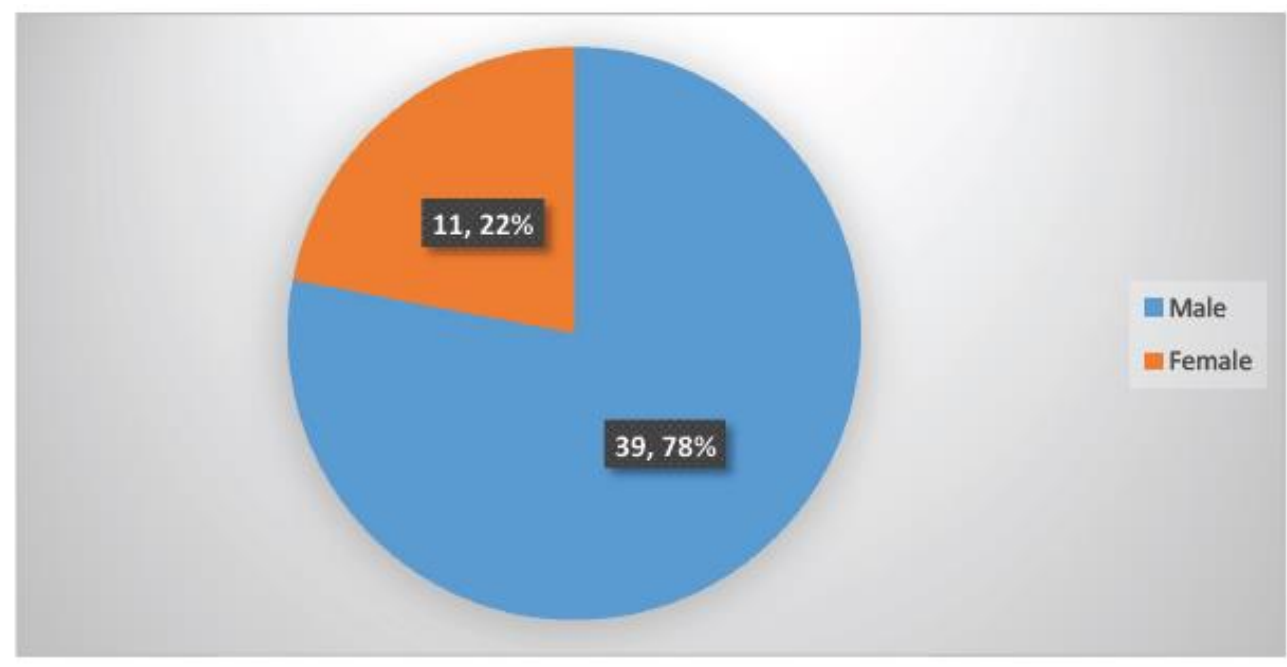

Figure 2. Shows the demographic signature of participants

The demographic signature showed 11 male participants (22\%) and 39 female participants (78\%) were responded out of 50

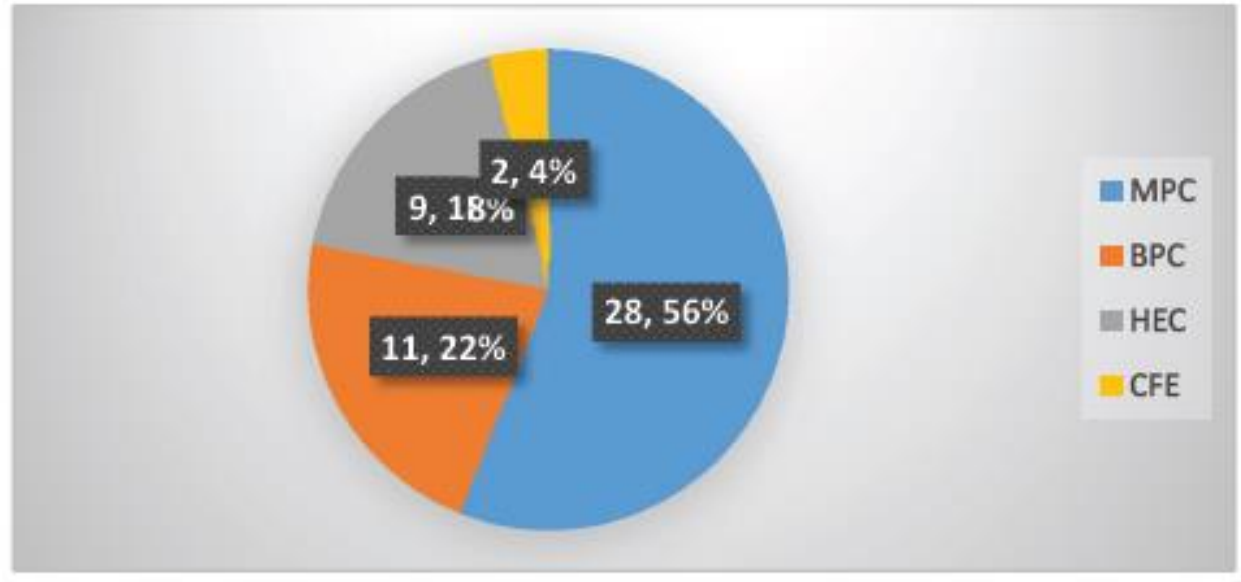

Figure 3. Demonstrates the distribution of adolescents enrolled in various majors

Figure-2 reveals the sharing of participants who part of the study among multiple majors. A 28 (56\%) of the adolescents who participated in the survey belonged to Maths, physics and chemistry (MPC) domain. While $11(22 \%)$ subjects were from biology, physics and chemistry discipline. And $9(18 \%)$ of study subjects are from the subject areas of history, economics and civics (HEC). Furthermore, 2(4\%) of the adolescents were enrolled in commerce, economics and civics (CEC). 


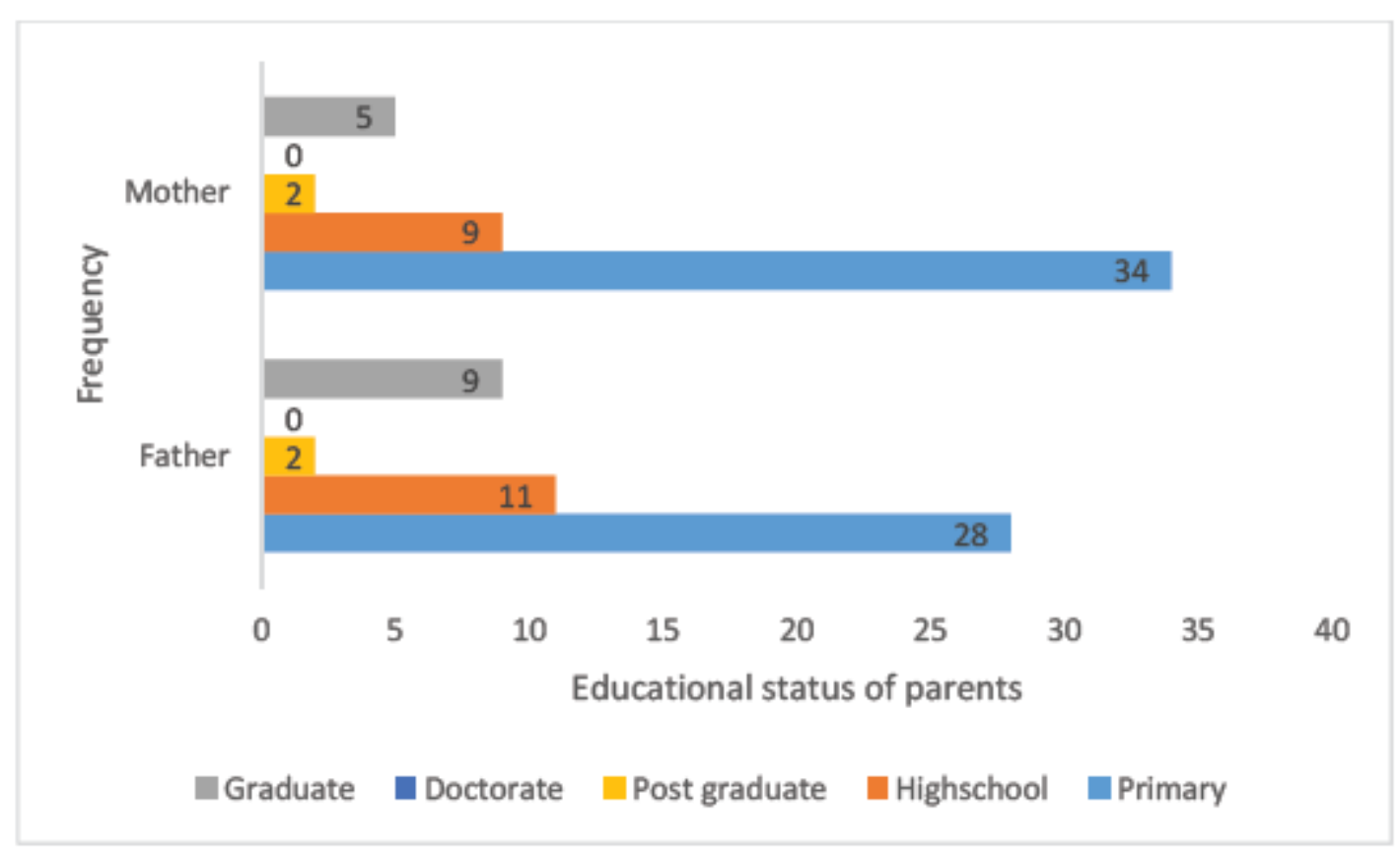

Figure 4. Exhibits the distribution of educational status of parents

Figure-3 demonstrates the literacy status of the parents; overall literacy found high among maternal side in comparison with a paternal side. Interestingly $34(68 \%)$ mothers had an education up to a primary level in contrast with fathers $28(59.5 \%)$. Although, 11(22\%) of a father having high school level literacy when compared to mothers $9(18 \%)$. While; $9(18 \%)$ of fathers having the graduate level of education about mothers $5(10 \%)$. Moreover, equal level $2(4 \%)$ of postgraduate training found among parents. And none of the parent's qualification not met up to the doctoral degree.

\section{Discussion}

To the best of our knowledge, hardly any studies reported about the perception of refractive error among adolescents, especially from the rural population, in India. By obtaining the perception from participants doesn't mean that adolescent's population have the high level of perception about spectacle wear and public health education is adequate. The present study gives an idea that $72 \%$ of respondent "strongly agree" that eye examination is an integral part of eye health. Likewise, $74 \%$ of subjects strongly agree that vitamin intake can play the crucial role in vision correction and AGARWAL, R., \& DHOBLE P. (2013) supported this, argues that the most common cause of poor vision is due to nutritional deficiency showed up to $68 \%$. The difference in the perception level of vitamin in taking from the current study is due to sample size probably attributed to the variation in the percentage. Interestingly $64 \%$ of the respondents "Strongly agree" vision correction and lifestyle plays the major role in eye health. Furthermore, $42 \%$ of the respondents "strongly agree" that vision correction should have done by an eye expert. AKS. M. R. (2013) supported this finding, reported that. $31.6 \%$ of the participants prefer to get eye examined by an ophthalmologist. While $66 \%$ of the participants expressed as "strongly agree" poor vision can lead to the shape of the eyeball. Similarly, $56 \%$ of the study subjects replied as" strongly agree "when it comes to an excessive use of electronic devices. Which can have negative impact on the visual system. And this observation was strongly supported by a study on ("Electronic gadgets and its effect on the eye", 2018) documented that electronic devices uses can cause the effect of UV rays in the eye, which leads to eye strain, redness, decrease vision and dry eye. Also, the fixation ability of the eye also will be declined due to excessive use of electronic gadgets. On the other hand, $28 \%$ of the subjects in the current study responded as "agree" that myopia more commonly seen in the youth population. This finding is in favour of a study conducted by the researchers 
DOI: $10.21522 / \mathrm{TIJPH} .2013 .06 .02 . A r t 013$

ISSN: $2520-3134$

argues that Castanon Holguin AM et al. (2007) and Congdon $\mathbf{N}$ et al. (2008) reported in a study that approximately 605 of Chinese students have myopia

And $32 \%$ of the participants perceived as "agree" that hyperopia is more common among geriatric population. However, $40 \%$ of the participants expressed as "strongly disagree" Low vision can lead to refractive correction issues. And in the present study, 30\% of the participants responded as "strongly disagree" wearing glass not because any cosmetic blemish and most of the contestant instead prefer to wear spectacle. Whereas in a study conducted by Parag Dhoble et al. (|2013) reported that $32 \%$ respondents expressed as glass were cosmetically unacceptable and it causes social stigma in comparison with the present study. And another study was done by SheetalSavur (2011). Mentioned that $51 \%$ of respondents felt that spectacles were is a cosmetic blemish.

\section{Conclusion}

To summarise, our so far finding suggests that, perception related to refractive error among adolescents from the rural background with a deprived district of Andhra Pradesh found to be poor. Moreover, a majority of the participants not known the fact that poor vision can have a significant impact on vision correction due to the influence of socioeconomic background and educational status of participants. To further comments on this extensive study should be conducted for further correlation with large sample size. Our finding suggestive of there is high needs for health education requirement when it comes to the perception of refractive error among adolescents especially the deprived districts of India.

\section{Limitations of the study}

The smaller sample size was considered for analysis. A lack of data related to a perception of refractive error for the references.

\section{Acknowledgement}

My sincere gratitude to the students who willing to share the information and the teaching and nonteaching staff of the Palasa Govt Junior college, Srikakulam district, Andhra Pradesh, India.

\section{References}

[1]. AGARWAL, R., \& DHOBLE, P. (2013). Study of the knowledge, attitude and practices of refractive error with emphasis on spectacle usages in students of rural central India. Journal of biomedical and pharmaceutical research, 2(3).

[2]. AK, S. M. R. (2013). Awareness and attitude toward refractive error correction methods: a population-based study in Mashhad. Journal of patient safety \& quality improvement, 1(1), 23-29.

[3]. Chia, E. M., Wang, J. J., Rochtchina, E., Smith, W., Cumming, R. R., \& Mitchell, P. (2004). Impact of bilateral visual impairment on health-related quality of life: the Blue Mountains Eye Study. Investigative Ophthalmology \& Visual Science, 45(1), 71-76.

[4]. Congdon, N., Wang, Y., Song, Y., Choi, K., Zhang, M., Zhou, Z. ... \& Wu, B. (2008). Visual disability, visual function, and myopia among rural Chinese secondary school children: the Xichang Pediatric Refractive Error Study (X-PRES)—report 1. Investigative ophthalmology \& visual science, 49(7), 2888-2894.

[5]. Dhoble, P., Agarwal, R., Patel, C., Anand, G., Sharma, J., \& Sabde, Y. (2013). Study to assess the psychosocial aspects of refractive errors and effectiveness of health education in correcting stigmas related to spectacle use in highschool students of rural India.

[6]. Electronic gadgets and its effect on the eye. (2018). Retrieved from http://www.medimanage.com/my-health-atwork/more-articles/electronic-gadgets-and-its-effect-on-the-eye.aspx.

[7]. Gomez-Salazar, F., Campos-Romero, A., Gomez-Campaña, H., Cruz-Zamudio, C., Chaidez-Felix, M., LeonSicairos, N. ... \& Martinez-Garcia, J. J. (2017). Refractive errors among children, adolescents and adults attending eye clinics in Mexico. International journal of ophthalmology, 10(5), 796.

[8]. He, M., Huang, W., Zheng, Y., Huang, L., \& Ellwein, L. B. (2007). Refractive error and visual impairment in school children in rural southern China. Ophthalmology, 114(2), 374-382. 
[9]. Javali, S. B., Gudaganavar, N. V., \& Raj, S. M. (2011). Effect of varying sample size in estimation of coefficients of internal consistency.

[10]. Kevin M. Sullivan, a. (2018). OpenEpi - Toolkit Shell for Developing New Applications. Retrieved from http://www.openepi.com/SampleSize/SSPropor.htm.

[11]. LLK Lin, YF Shih, CK Hsiao, CJ Chen (1983 to 2000).Prevalence of myopia in Taiwanese schoolchildren: " Annals Academy of Medicine Singapore 33, no. 1 (2004): 27-33.

[12]. Pascolini, D., \& Mariotti, S. P. (2012). Global estimates of visual impairment: 2010. British Journal of Ophthalmology, 96(5), 614-618.

[13]. SheetalSavur (2011). The perceptions regarding refractive errors and their psychosocial impact on youth in Dakshina Kannada. Journal of Clinical and Diagnostic Research. 2011 August, Vol-5(4): 746-748746 746J.

[14]. Williams, K. M., Verhoeven, V. J., Cumberland, P., Bertelsen, G., Wolfram, C., Buitendijk, G. H., \& Höhn, R. (2015). Prevalence of refractive error in Europe: the European eye epidemiology (E3) Consortium. European journal of epidemiology, 30(4), 305-315.

[15]. World Health Organization. (2013). Universal eye health: a global action plan 2014-2019. 